\title{
SCIDOC
}

International Journal of Clinical Dermatology \& Research (IJCDR)

ISSN : 2332-2977

\section{Human Myiasis in Yemen: A Case Report of an Extensive Oral Myiasis in a Rural Girl}

Case Report

\author{
Al-Kamel MA ${ }^{1,2^{*}}$ \\ ${ }^{1}$ Chair, Regional Leishmaniasis Control Center (RLCC), Yemen. \\ ${ }^{2}$ Department of Dermatology, Sana'a University Hospital, Sana'a, Yemen.
}

\section{Abstract}

Reported cases of extensive oral myiasis in the literature are still scarce, particularly from Yemen. This report aims to present the first case, as up to my knowledge, of extensive oral myiasis in a girl who was clearly predisposed to infestation. It concluded that several entities of myiasis, which can be referred to as a disease of the poor, are endemic in Yemen. Climate change, illiteracy, the practice of keeping domestic animals indoors, constant increases in flies populations, deteriorating social and economic conditions and improper housing, hygiene and sanitation explain the high incidence of fly-borne diseases in Yemen. Further molecular studies are needed to identify all responsible strains.

Keywords: Oral myiasis; Fly; Screwworm; Larvae; Maggots; Yemen.

\section{Introduction}

Myiasis, also known as 'fly-strike' or 'fly-blown', is infestation of human or animal tissues with the voracious larvae (maggots) of insects of order Diptera (true flies). The crawling movement of these larvae provokes irritation, may destroy healthy tissues and can result in serious or even fatal complications. Human myiasis is a rare worldwide condition, more common in poor socio-economic regions with warm-humid climate [1].

Oral myiasis, first described by Laurence in 1909, is a rare entity referring to the invasion of oral cavity tissues by fly larvae, and often associated with various medical and anatomical conditions, such as poor hygiene, mouth breathing, mental retardation and incompetent lips [2-4].

Here, I report an unusual case of extensive oral myiasis in a girl, from Yemen, with poor oral hygiene and mental impairment. This case gains significance owing to its rarity and the need to be aware of diagnosis and treatment if at all it presents in a physician's clinical practice.

\section{Case Report}

In September 2016, a 16-year-old rural girl from a village of Barat district, Al-Jawf governorate (Northeastern region of Yemen), was presented to my office in Sana'a (the capital city) complaining of two neglected, inflamed wounds on her left cheek with foul odor and thick gray purulent discharge for five-month duration.

Clinical examination revealed (Figures. 1-3), left mouth angle extensive, lacerating, necrotic wound, extended to both lips, infiltrated the underlying maxillofacial tissues with an averted, erythematous border; lateral deep wound manifested with areas of gangrene and putrefaction, purulent and offensive drainage and an orocutaneous fistula that penetrates at a point in its base at the left maxillary dentoalveolar region; and a very poor oral hygiene. Vital data and routine blood testing results were within normal.

History revealed that, mouth breathing during sleep, mental impairment and unhygienic living conditions; family keeps livestock indoors (including sheep and cows); big number of horizontally segmented whitish black screwworms (maggots) were crawling out from the wounds that had been manually extracted by a local health officer (Figure 4); history of trauma was irrelevant.

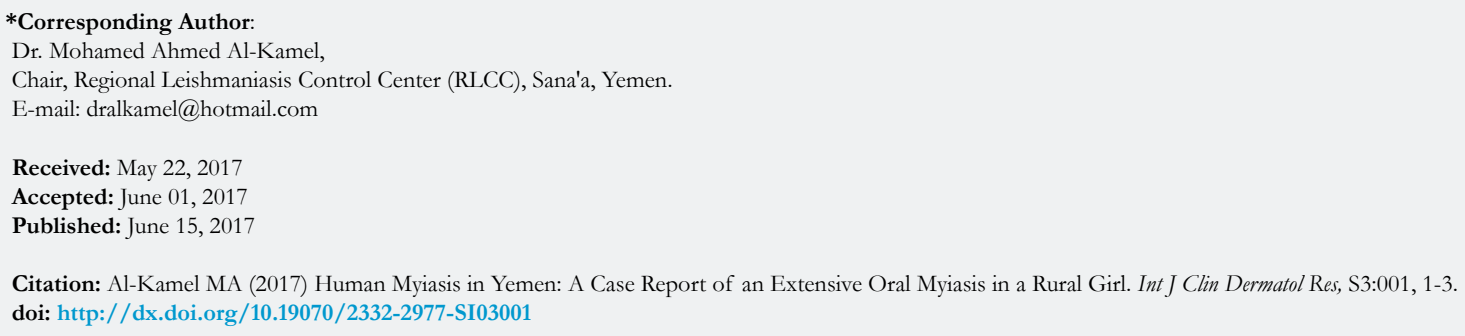

Copyright: Al-Kamel $\mathbf{M A}^{\circ}$ 2017. This is an open-access article distributed under the terms of the Creative Commons Attribution License, which permits unrestricted use, distribution and reproduction in any medium, provided the original author and source are credited. 
Figure 1. Photograph Showing the Presenting Lesions (anterior view).

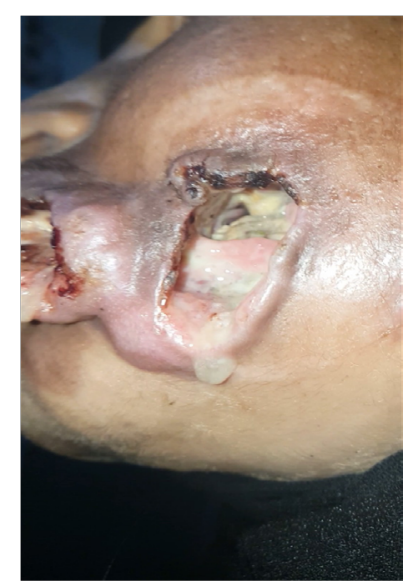

Figure 2. Photograph Showing the Presenting Lesions (anterolateral view).

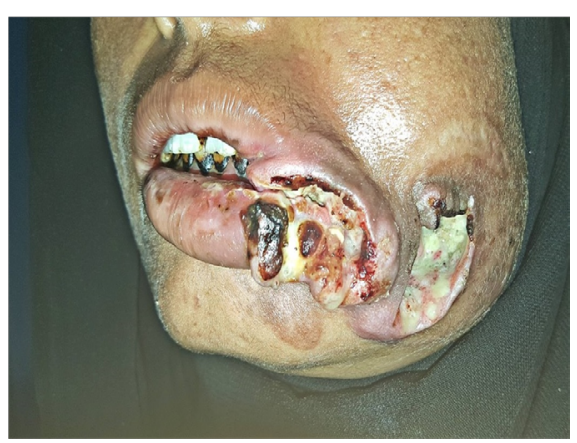

Figure 3. Photograph Showing the Presenting Lesions (lateral view).

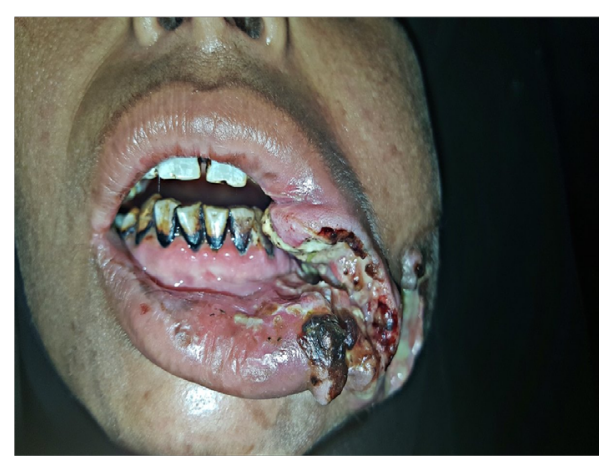

Figure 4. Photograph Showing the Causative Agents (Chrysomya bezziana).

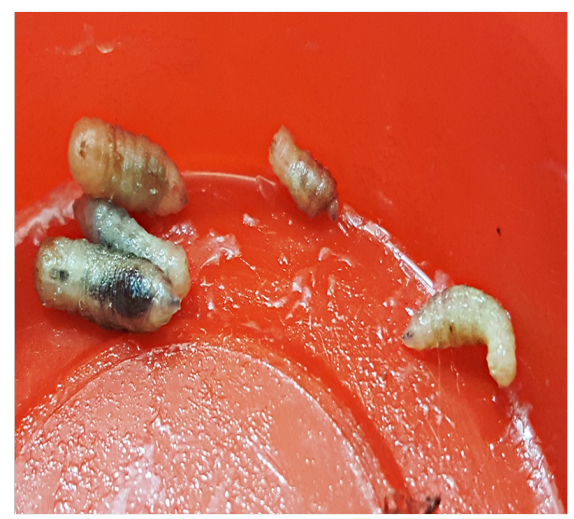


Based on clinical examination and history, provisional diagnosis of oral myiasis infestation with Old World screwworm Chrysomya bezziana was made.

Therapy with oral ivermectin, tetracycline and analgesic was initiated, and then patient was referred to another surgical public service for further management, including investigation of any possible, concurrent neoplastic disorder.

Four weeks later, patient's uncle reported that patient's condition has been markedly improved.

\section{Discussion}

Human myiasis is an infection caused by voracious dipterous larvae, which feed upon host's living tissues, dead tissues or ingested food. A useful scheme of categorization is based on the anatomical location of the infection, as following, (1) cutaneous myiasis; (2) furuncular and migratory myiasis; (3) wound myiasis; (4) cavitary myiasis. Cutaneous myiasis and wound myiasis are the most frequently encountered clinical forms.

Calliphoridae or Blowflies (timbu flies, screwworms, green bottles), Sarcophagidae (flesh fly) and Oestridae (warble flies and bottle fly) are the main families of flies responsible for human myiasis [5].

Oral myiasis is a rare and unique presentation of cavity myiasis owing to the fact that myiasis develops by direct infestation of tissues by larvae laid by flies and oral cavity rarely provides a favorable site for infestation, and almost all reported cases were rural inhabitants. Usually, it is associated with poor oral hygiene (the most important risk factor), severe halitosis, suppurating lesions, gingival disease, trauma, mental debility and with people who maintain their mouths open for long period $[6,7]$.

Chrysomya bezziana (old World screwworm) is an obligatory flesheating parasite, belonging to the family Calliphoridae and characterized by armed, broad, encircling bands of spines that resembles the threads of a screw. Infestation with $C$. bezziana might be distinguish from that with other Chrysomya species by its burrowing capabilities, toxins-induced destruction and the foul smelling discharge frequently released by infected tissues [8].

Although the principal treatment of myiasis depends on manual removal of the maggots and surgical debridement of the infected tissues, pharmacological therapies with oral doxycycline or other locally asphyxiating and systemic acting drugs are emerging in some cases for faster and better recovery [4].

In Yemen, myiasis was first reported in December 2007; some 464 animals have died of the disease in 2008; and a new outbreak of screwworm in Taiz, Ibb and Dhamar governorates in central
Yemen has killed hundreds of livestock, particularly in 2016 [9, $10]$.

Although the literature covers cutaneous and genitourinary myiasis has been reported from the previously mentioned areas [11], this is the first report prescribing a case with such extensive oral myiasis in Yemen.

In the present report, the patient was clearly predisposed to the infestation considering the fact she had unhygienic condition, mouth breathing and mental impairment. However, reported history failed to clarify the underlying cause of the necrotic lesions and whether the current patient had a secondary myiasis on top of a previous disease, such as noma or malnutrition, or a primary myiasis where the flesh-eating Chrysomya b. parasites were responsible for the massive destruction of oral tissues the current patient further complained.

This patient resembled the fifth case of myiasis infection the author had managed within a month; the other four cases were furuncular myiasis from Central and Northern regions of Yemen, which conclude that several entities of myiasis are prevalent in Yemen.

Climate change, rising temperature, illiteracy, the practice of keeping domestic animals indoors, constant increases in flies populations, deteriorating social and economic conditions and improper housing, hygiene and sanitation may explain the high prevalence of some fly-borne diseases in Yemen, such as leishmaniasis and myiasis, which can be referred to as diseases of the poor $[12,13]$.

\section{References}

[1]. Duque FL, Ardila CM (2011) Oral Myiasis Caused by the Screwworm Cochliomyia Hominivorax Treated With Subcutaneous Ivermectin and Creolin: Report of Six Cases After Trauma. Dent Traumatol. 27(5) : 404-407.

[2]. Laurence SM (1909) Dipterous larvae infection. BMJ. 9: 88.

[3]. Reddy MHR, Das N, Vivekananda MR (2012) Oral myiasis in children. Contemp Clin Dent. 3(1): 19-22.

[4]. Al-Maweri SA, Al-Sufyani GA, Tarakji B, Abdulrab S (2015) Myiasis Associated with Oral Squamous Cell Carcinoma--A Literature Review. Asian Pac J Cancer Prev. 16(12): 4997-9.

[5]. Yadav S, Tyagi S, Kumar P, Puri N (2014) Oral myiasis involving palatal mucosa of a young female. J Nat Sci Biol Med. 5(1): 194-7.

[6]. Vinit GB, Jayavelu P, Shrutha SP (2013) Oral myiasis in a maxillofacial trauma patient. J Pharm Bioall Sci. 5(2): 195-7.

[7]. Francesconi F, Lupi O (2012) Myiasis. Clin Microbiol Rev. 25(1): 79-105.

[8]. Khanna V, Singh A, Gupta S, Behl M (2014) Extensive oral myiasis. J Cranio Max Dis. 3(1) : 65-7.

[9]. IRIN News (2008) Struggling to combat maggot attacks. November, 2016

[10]. Reuters News . November, 2016.

[11]. Al-Malmi MA (2014) Myiasis in Republic of Yemen (cutaneous myiasis three cases reported and genito-urinary myiasis three cases reported). Ann Trop Med Public Health. 7(5): 238-43.

[12]. Al-Kamel MA (2016) Spectrum of winter dermatoses in rural Yemen. Int J Dermatol. 55(5): 512-17.

[13]. Al-Kamel MA (2016) Leishmaniasis in Yemen: a clinicoepidemiological study of leishmaniasis in central Yemen. Int J Dermatol. 55(8): 849-55. 